\title{
Hubungan Pengetahuan Siswa Palang Merah Remaja dengan Tindakan Pertolongan Pertama Penderita Sinkop di Madrasah Tsanawiyah Negeri 1 Bukittinggi
}

\author{
Vita Febrina ${ }^{1}$, Rima Semiarty $^{2}$, Abdiana $^{2}$
}

\begin{abstract}
Abstrak
Sinkop ialah suatu keadaan hilangnya kesadaran seseorang secara tiba-tiba. Penderita sinkop membutuhkan pertolongan cepat dan tepat untuk mencegah kondisi penderita semakin menurun, tetapi sebagian orang tidak mengetahui cara penanggulangannya. Tujuan penelitian ini adalah menentukan hubungan antara pengetahuan anggota Palang Merah Remaja (PMR) dan tindakan pertolongan pertama penderita sinkop di MTsN 1 Bukittinggi. Penelitian analitik ini menggunakan rancangan cross sectional study. Subjek adalah 47 orang anggota PMR MTsN 1 Bukittinggi tahun ajaran 2013-2014 yang memenuhi kriteria inklusi dan eklusi. Analisis yang digunakan adalah uji chisquare. Hasil studi ialah 72,3\% anggota PMR MTsN 1 Bukittinggi memiliki pengetahuan yang baik tentang sinkop dan $27,7 \%$ kurang baik. Ada $51,1 \%$ anggota memiliki tindakan yang baik dalam pemberian pertolongan pertama pada penderita sinkop dan $48.9 \%$ anggota memiliki tindakan yang kurang baik. Berdasarkan hasil penelitian, diperoleh hubungan antara pengetahuan anggota PMR dengan tindakan pertolongan pertama penderita sinkop di MTsN 1 Bukittinggi ( $p=0,024$ derajat kemaknaan $p<0,05$ ). Simpulan studi ini adalah sebagian besar anggota PMR MTsN 1 Bukittinggi memiliki pengetahuan dan tindakan pertolongan pertama yang baik pada penderita sinkop.
\end{abstract}

Kata kunci: sinkop, pertolongan pertama, pengetahuan, tindakan

\begin{abstract}
Syncope is a condition of the sudden loss conscious. The syncope patient must be helped quickly and precisely to prevent the condition of the patient be getting worse. There are some people don't know how to provide aid. The objective of this study was to determine the relationship between the knowledge of Red Cross Student (PMR) and the first aid measures for syncope patient at MTsN1 Bukittinggi. This is analytic studies by a cross-sectional design. The subjects were 47 PMR students at the first degree of MTsN 1 in 2013-2014 school year that have the criteria for inclusion and exclusion. This study using chi-square analysis. Researcher obtained $72.3 \%$ of PMR student at MTsN 1 Bukittinggi have good knowledge about syncope and $27.7 \%$ unfavorable. There were $51,06 \%$ student that have a good action in giving first aid for syncope patient and 48,9\% have poor action in giving first aid. The results of this study showed the relationship between the knowledge of PMR student and the first aid measures for syncope patient at MTsN1 Bukittinggi that can be given to the syncope patient ( $p=0.024$ at significant $p$ value $<0,05)$. The conclusion is the most of PMR students in MTSN 1 Bukittinggi have good knowledge and good action in giving first aid for syncope. Keywords: syncope, first aid, knowledge, action

Affiliasi penulis: 1. Prodi Profesi Dokter FK Unand (Fakultas Kedokteran Universitas Andalas Padang 2. Bagian IImu Kesehatan Masyarakat FK Unand.

Korespondensi: Vita Febrina, Email: febrina.vita@yahoo.co.id Telp: 085766280713

\section{PENDAHULUAN}

Sinkop merupakan suatu keadaan hilangnya kesadaran dan kekuatan tubuh seorang individu yang terjadi secara mendadak, serta disertai dengan pemulihan kondisi individu tersebut. ${ }^{1}$
\end{abstract}


Penderita sinkop memiliki prognosis yang bervariasi, mulai dari mortalitas rendah hingga mortalitas tinggi, hal ini tergantung pada umur, gender, serta etiologi. Penderita yang pernah mengalami sinkop juga memiliki kemungkinan untuk terjadinya rekurrensi, tetapi ini juga tergantung pada penyebab yang mendasarinya. ${ }^{1}$

Individu yang pernah mengalami episode sinkop tanpa dapat diketahui penyebabnya memiliki angka mortalitas yang lebih tinggi dibandingkan individu yang tidak pernah mengalami sinkop. ${ }^{2}$

Pemberian pertolongan yang cepat dan tepat kepada penderita yang membutuhkan pertolongan terutama di sekolah maka diperlukan pertolongan dari anggota Palang Merah Remaja untuk mencegah kondisi korban lebih buruk, tetapi seringkali saat ingin memberikan pertolongan pada penderita, penolong tidak tahu caranya sehingga malah menyakiti si penderita. $^{3}$

Palang Merah Remaja (PMR) merupakan pengembangan dari Palang Merah Indonesia (PMI) yang memiliki kegiatan kemanusiaan di bidang kesehatan. ${ }^{4}$

Hasil pengamatan mendapatkan kejadian sinkop juga sering dialami oleh siswa-siswi di MTsN 1 Bukittinggi. MTsN ialah sekolah formal yang setingkat dengan sekolah menengah pertama. Berdasarkan keterangan dari pembina Palang Merah Remaja di MTsN 1 Bukittinggi maka diketahui sinkop paling sering terjadi pada hari Senin yaitu saat siswa-siswi sedang melaksanakan upacara bendera di sekolah dan siswa-siswi yang sinkop pada saat itu dapat mencapai empat hingga lima orang.

Hal ini disebabkan karena MTsN 1 Bukittinggi ialah sekolah yang memiliki citra serta pendidikan yang sangat berkualitas sehingga banyak diantara siswa-siswi yang tempat tinggalnya jauh tetap memilih untuk bersekolah disana, sehingga pada saat masuk sekolah tidak sempat untuk sarapan dan merasa keletihan dalam perjalanan, sehingga mudah mengalami sinkop di sekolah. Pada saat kejadian sinkop berlangsung, maka diperlukan bantuan dari anggota Palang Merah Remaja untuk membantu siswa-siswi yang pingsan.
Pengetahuan yang baik serta pertolongan pertama yang benar sangat diperlukan oleh anggota Palang Merah Remaja agar mampu memberikan pertolongan pertama yang cepat dan tepat pada siswa-siswi yang mengalami sinkop tanpa harus menunggu arahan dari pembina PMR atau guru yang berada di lokasi kejadian.

Oleh karena itu penting sekali bagi anggota Palang Merah Remaja memiliki ilmu pengetahuan tentang pertolongan pertama. Diharapkan dengan ilmu yang dimilikinya anggota Palang Merah Remaja mampu melakukan pertongan pertama pada siswa pingsan sebelum dibawa ke rumah sakit agar prognosa yang didapatkan lebih baik.

\section{METODE}

Penelitian ini bersifat analitik dengan menggunakan rancangan cross-sectional study. Populasi penelitian ini adalah siswa MTsN 1 Bukittinggi yang terdaftar dalam ekstrakulikuler PMR pada tahun ajaran 2013-2014 dengan jumlah 55 orang. Subjek penelitian ini adalah 47 anggota PMR MTsN 1 Bukittinggi yang mengikuti kegiatan ekstrakurikuler tahun ajaran 2013-2014 yang memenuhi kriteria inklusi dan eklusi.

Kriteria inklusi sampel ialah siswa yang aktif dalam kegiatan PMR, siswa yang bersedia menjadi responden, siswa yang terdaftar di MTsN 1 Bukittinggi pada tahun ajaran 2013 - 2014. Kriteria eklusi sampel ialah siswa yang tidak hadir pada saat pengumpulan data di sekolah, siswa kelas tiga MTsN 1 Bukittinggi yang sedang mengikuti ujian nasional. Teknik pengambilan sampel dilakukan dengan teknik total sampling dimana seluruh populasi yang menjadi anggota akan diamati sebagai sampel.

Variabel independent penelitian ialah pengetahuan tentang sinkop. Variabel dependent ialah tindakan pertolongan pertama. Penelitian ini dilakukan dengan menggunakan kuisioner yang telah dilakukan uji validitas dan reliabilitas.

Data yang diperoleh dianalisis dengan menggunakan uji chi-square dengan batas kemaknaan 0,05, dikatakan bermakna apabila nilai $p<$ 0,05 dan tidak bermakna jika $p>0.05$. 
HASIL

\section{Deskripsi Karakteristik Responden}

Deskripsi karakteristik responden dapat dilihat pada Tabel 1.

Tabel 1. Karakteristik responden

\begin{tabular}{lcc}
\hline \multicolumn{1}{c}{ Karakteristik } & $\mathbf{n}$ & $\%$ \\
\hline Jenis kelamin & 7 & $14,9 \%$ \\
Laki - laki & 40 & $85,1 \%$ \\
Perempuan & 1 & \\
\hline Umur & 16 & $2,1 \%$ \\
12 tahun & 26 & $34 \%$ \\
13 tahun & 4 & $55,3 \%$ \\
14 tahun & & $8,5 \%$ \\
15 tahun & & \\
\hline Tahun terdaftar sebagai & 22 & $46,8 \%$ \\
anggota PMR & 25 & $53,2 \%$ \\
2012 & 25 & $53,2 \%$ \\
2013 & $\mathbf{4 7}$ & $\mathbf{1 0 0} \%$ \\
\hline Kelas & & \\
VII & $22,8 \%$ \\
VIII & 25 \\
\hline Total & & \\
\hline
\end{tabular}

Pada Tabel 1 menunjukkan karakteristik responden berdasarkan jenis kelamin responden perempuan lebih banyak $(85,1 \%)$ dibandingkan lakilaki $(14,9 \%)$. Berdasarkan umur didapatkan bahwa jumlah responden terbanyak berumur 14 tahun (55.3\%). Berdasarkan tahun terdaftar responden terbanyak terdaftar pada tahun 2013 (53,2\%) dan berdasarkan kelas responden terbanyak berada pada kelas VII $(53,2 \%)$.

\section{Analisis Univariat}

Distribusi frekuensi derajat pengetahuan anggota PMR MTsN 1 Bukittinggi tentang sinkop dapat dilihat pada Tabel 2

Tabel 2. Distribusi pengetahuan anggota PMR MTsN 1 Bukittinggi tentang sinkop

\begin{tabular}{ccc}
\hline $\begin{array}{c}\text { Kategori } \\
\text { pengetahuan }\end{array}$ & $\mathbf{n}$ & $\%$ \\
\hline Kurang Baik & 13 & $27,7 \%$ \\
Baik & 34 & $72,3 \%$ \\
\hline Total & $\mathbf{4 7}$ & $\mathbf{1 0 0 \%}$ \\
\hline
\end{tabular}

Pada Tabel 2 didapatkan 13 orang $(27,7 \%)$ dengan kategori kurang baik dan 34 orang (72,3\%) dengan kategori baik.

Distribusi frekuensi derajat pengetahuan anggota PMR MTsN 1 Bukittinggi tentang pertolongan pertama pada penderita sinkop dapat dilihat pada Tabel 3.

Tabel 3. Distribusi tindakan anggota PMR MTsN 1 Bukittinggi tentang sinkop

\begin{tabular}{ccc}
\hline Kategori Tindakan & $\mathbf{N}$ & $\%$ \\
\hline Kurang baik & 23 & $48,9 \%$ \\
Baik & 24 & $51,1 \%$ \\
\hline Total & $\mathbf{4 7}$ & $\mathbf{1 0 0 \%}$ \\
\hline
\end{tabular}

Dari Tabel 3 didapatkan 23 orang $(48,9 \%)$ dengan kategori kurang baik dan 24 orang $(51,1 \%)$ dengan kategori baik.

\section{Analisis Bivariat}

Hasil uji statistik untuk melihat hubungan pengetahuan anggota PMR dengan tindakan pertolongan pertama pada penderita sinkop dapat dilihat pada Tabel 4.

Tabel 4. Hubungan pengetahuan anggota PMR tentang sinkop dengan tindakan pertolongan pertama pada penderita sinkop di MTsN 1 Bukittinggi

\begin{tabular}{lccccccc}
\hline \multirow{2}{*}{$\begin{array}{c}\text { Pengeta } \\
\text { huan }\end{array}$} & \multicolumn{9}{c}{ Tindakan } & & & \\
& \multicolumn{2}{c}{ Baik } & & & & & \\
& f & $\%$ & $\mathrm{f}$ & $\%$ & $\mathrm{f}$ & $\%$ & \\
\hline $\begin{array}{l}\text { Kurang } \\
\text { Baik }\end{array}$ & 10 & 76,9 & 3 & 23,1 & 13 & 100 & \\
Baik & 13 & 38,2 & 21 & 61,8 & 34 & 100 & \\
\hline Jumlah & $\mathbf{2 3}$ & $\mathbf{4 8 , 9}$ & $\mathbf{2 4}$ & $\mathbf{5 1 , 1}$ & $\mathbf{4 7}$ & $\mathbf{1 0 0}$ & \\
\hline
\end{tabular}

Tabel 4 menunjukkan bahwa hasil uji statistik chi-square didapatkan nilai $\mathrm{p}=0,024$ yang berarti terdapat hubungan yang bermakna antara pengetahuan anggota PMR dengan tindakan pertolongan pertama pada penderita sinkop 


\section{PEMBAHASAN}

\section{Gambaran Umum Palang Merah Remaja Madrasah} Tsanawiyah Negeri 1 Bukttinggi

MTsN 1 Bukittinggi ialah salah satu sekolah yang terletak di Provinsi Sumatera Barat. PMR MTsN 1 Bukittinggi ini beranggotakan 55 orang siswa pada tahun ajaran 2013-2014, sedangkan penelitian ini dilakukan kepada seluruh anggota PMR MTsN 1 Bukittinggi yang telah memenuhi kriteria inklusi dan eklusi. Oleh karena itu maka diperoleh responden yang memenuhi kriteria inklusi dan ekslusi berjumlah 47 orang.

\section{Analisis Univariat}

Pengetahuan

Setelah dilakukan penelitian pada 47 responden pada anggota PMR MTsN 1 Bukittinggi tentang sinkop dan pertolongan pertama pada maka diperoleh hasil 34 responden $(72,3 \%)$ berada dalam kategori pengetahuan yang baik, artinya responden menguasai $>75 \%$ pengetahuan tentang sinkop dan 13 responden $(27,7 \%)$ berada dalam kategori pengetahuan yang kurang baik, artinya responden menguasai $\leq 75 \%$ pengetahuan tentang sinkop.

Menurut Effendi dan Makhfudli yang terdapat dalam penelitan Bala et al menjelaskan, pengetahuan individu dikatakan baik dalam arti bahwa pengetahuan berada dalam kategori memahami (comprehension), memahami dapat diartikan sebagai kemampuan seseorang dalam menjelaskan secara benar objek atau materi yang telah diketahui, serta orang tersebut mampu untuk mengeinterpretasikan objek atau materi tersebut secara benar. ${ }^{5}$

Menurut penelitian Maolinda et al pada tahun 2012 pengetahuan seorang individu dinilai cukup atau kurang kemungkinan karena situasi dan kondisi pada saat pemberian pendidikan kesehatan tidak menyeluruh dan metode yang digunakan untuk memberikan pendidikan ialah melalui metode ceramah. Salah satu kekurangan dalam metode ceramah karena terdapat keterbatasan seorang individu dalam menyerap informasi melalui pendengaran. ${ }^{6}$

Ternyata pemberian informasi melalui diskusi kelompok lebih baik dibandingkan pemberian informasi melalui metode ceramah. ${ }^{7}$
Hal ini dapat dibuktikan dengan hasil penelitian pada anggota PMR MTsN 1 Bukittinggi yang umumnya memiliki pengetahuan yang baik dan hanya sebagian kecil yang memiliki pengetahuan yang cukup dan kurang, salah satu penyebabnya ialah karena pemberian pendidikan kesehatan yang diberikan bukan hanya menggunakan metode ceramah saja, tetapi metode yang digunakan ialah metode ceramah dan diiringi dengan metode diskusi.

\section{Tindakan}

Setelah dilakukan penelitian pada 47 anggota PMR MTsN 1 Bukittinggi tentang tindakan pertolongan pertama pada penderita sinkop meliputi pertolongan pertama yang dapat diberikan pada saat menghadapi penderita sampai menyediakan trasportasi ke rumah sakit jika dibutuhkan, maka diperoleh hasil 24 responden $(51,1 \%)$ dapat melakukan tindakan pertolongan pertama dengan baik, 23 responden $(48,9 \%)$ kurang mampu memberikan pertolongan pertama dengan baik.

Menurut penelitian Karerina pada tahun 2013 tindakan dikatakan benar artinya tindakan yang dilakukan telah lebih dari $50 \%$, tindakan dikatakan tidak benar artinya tindakan yang dilakukan kurang dari $50 \%{ }^{8}$

Tindakan pemberian pertolongan pertama yang benar dapat menyelamatkan nyawa penderita mencegah terjadinya kecacatan, serta dapat menunjang terjadinya penyembuhan. ${ }^{9}$

Jadi dapat disimpulkan bahwa sebagian dari anggota PMR MTsN 1 Bukittinggi menguasai tindakan pertolongan pertama $>50 \%$ dan sebagian lagi menguasai tindakan pertolongan pertama $<50 \%$

\section{Analisis Bivariat}

Penelitian yang telah dilakukan ini sejalan dengan penelitian yang dilakukan oleh Hassanzaddeh et al pada tahun 2009 yang menyatakan bahwa seseorang yang memiliki pengetahuan mempunyai kemampuan yang lebih baik dalam pemberian pertolongan pertama dibandingkan dengan seseorang yang memberikan pertolongan pertama tanpa adanya pengetahuan, tetapi penelitian tersebut juga mengatakan bahwa jika pengetahuan ditambah dengan latihan melalui praktek di lapangan maka 
nantinya tindakan pertolongan pertama yang diberikan akan lebih baik lagi jika dibandingkan seseorang yang hanya memiliki pengetahuan saja tanpa diiringi dengan latihan melalui praktek di lapangan. ${ }^{10}$

Penelitian ini juga dipertegas oleh survei yang dilakukan oleh British Broad Casting Cooperation (BBC) yang dikutip dalam penelitian Imad et al pada tahun 2012 yang menyatakan setelah dilakukan survei di Inggris pada tahun 2000 yang dilakukan kepada 2000 orang yang telah menyaksikan acara televisi seperti Casuality dan Emergency room, acara tersebut bertujuan untuk memberikan pengetahuan mengenai pemberian pertolongan pertama, ternyata acara tersebut dapat mempengaruhi keberanian penonton untuk melakukan pertolongan pertama. ${ }^{11}$

Tindakan pertolongan pertama bertujuan untuk mencegah kondisi penderita lebih buruk, tetapi bila suatu tindakan pertolongan pertama yang diberikan tanpa pengetahuan maka terkadang malah akan menyakiti penderita. Oleh sebab itu dalam memberikan pertolongan pertama pada penderita sinkop di MTsN 1 Bukittinggi diperlukan pengetahuan yang dimiliki oleh anggota PMR.

\section{SIMPULAN}

Terdapat hubungan antara pengetahuan anggota PMR dengan tindakan pertolongan pertama penderita sinkop di MTsN 1 Bukittinggi.

\section{UCAPAN TERIMA KASIH}

Terima kasih kepada Fakultas Kedokteran Universitas Andalas atas kesempatan yang diberikan untuk melanjutkan pendidikan. Kepada MTsN 1 Bukittinggi sebagai tempat penelitian dan atas fasilitas yang telah diberikan.

\section{DAFTAR PUSTAKA}

1. Benditt, Jean DG, Blanck J, Brignole M, Sutton R. Syncope. Amerika: Blackwell; 2006.hlm.3-4.

2. Sudoyo AW, Setiyohadi B, Alwi I, Simadibrata M, Setiadi S. IImu penyakit dalam. Edisi ke-5. Jakarta: Pusat Penerbitan IImu Penyakit Dalam Fakultas Kedokteran Universitas Indonesia;2009.hlm.161-66
3. Tim Esensi. Mengenal UKS. Jakarta: Erlangga; 2012.hlm.33-4

4. Sumanto A. Petunjuk palang merah remaja. Jakarta: Arya Pustaka; 2011.hlm.1-2.

5. Bala DKY, Rakhmat A, Junaidi. Gambaran pengetahuan dan pelaksanaan bantuan hidup dasar perawat gawat darurat di instalasi gawat darurat (IGD) RSUD Labuang Baji Makassar. Jurnal IImiah Kesehatan Diagnosis. 2014; 4 (4): 457-62.

6. Maolinda N, Sriati A, Maryati I. Hubungan pengetahuan dengan sikap siswa terhadap pendidikan kesehatan reproduksi remaja di SMAN 1 Margahayu. Jurnal Fakultas IImu Keperawatan Universitas Padjajaran Bandung. 2012;1(1):1-15

7. Tarigan A. Disertasi efektivitas metode ceramah dan diskusi kelompok terhadap pengetahuan dan sikap tentang kesehatan reproduksi pada remaja di Yayasan Pendidikan Harapan Mekar Medan. 2010. (diunduh 17 Oktober 2014). Tersedia dari: URL: HYPERLINK http://repository.usu.ac.id/bitstream/ 123456789/2003/pdf.170ktober2014

8. Karerina PR, Nurjanah, Ernawati D. Perilaku lansia menopause dalam menjaga kesehatan reproduksinya di Posyandu Lansia Mawar Putih RW IX Kelurahan Gajah Mungkur Semarang. Fakultas Kesehatan Universitas Dian Suswanto. 2013; Article 10

9. Muhajir, Sutrisno B. Pendidikan jasmani, olahraga, dan kesehatan untuk SMP/MTs Kelas VII. Jakarta: Pusat Perbukuan Kementrian Pendidikan Nasional; 2013.hlm.203-6

10. Harsanzaddeh A, Vasli A, Zare. Effects of two educational method of lecturing and role playing on knowledge and performance of high school students in first aid at emergency scene. 2009. (diunduh 28 Juli 2014). Tersedia dari: URL: HYPERLINK http://www.ncbi.nlm.nih.gov/pmc/ articles/PMC3093028/.

11. Imad K, Sutanto $T$, Karsam. Rancang bangun aplikasi visualisasi pertolongan pertama berbasis mobile menggunakan teknologi J2ME. Jurnal Jurusan Sistem Informasi, Sekolah Tinggi Manajemen Informatika \& Komputer Surabaya. 2012;1(2):1-13 